\title{
Utilization of Contextual Knowledge Elements in 3D CAD Model Visualization from the Perspectives of Practicing Engineers
}

\author{
https://doi.org/10.3991/ijet.v14i24.12137 \\ Mohd Fahmi Adnan ${ }^{(凶)}$, Mohd Fadzil Daud, Muhammad Sukri Saud, \\ Wan Nazdah Wan Hussin \\ Universiti Teknologi Malaysia, Johor, Malaysia \\ famieadnan@gmail.com
}

\begin{abstract}
Today's industry force demands for knowledgeable and skillful engineering graduates in using modern Computer Aided Design (CAD) tools. However, current practices show that there is a lack of contextual knowledge among Mechanical Engineering undergraduates and fresh graduate engineers in utilizing 3D CAD modeling software to develop a good product design. Hence, a study to address this issue is conducted by focusing on the representation of contextual knowledge in 3D CAD modeling. This article focused on presenting essential elements of contextual knowledge utilized among practicing engineers in their daily design works, in the aspect of Model Visualization. This study was conducted using a transcendental phenomenology approach. Four practicing engineers from engineering department of one shipbuilding company in Peninsular Malaysia were purposively selected to be studied. From the analysis, there are three most frequent emerging themes in the application of contextual knowledge in visualizing and presenting model using 3D CAD modeling: Realization, Design Intention and Normalization. These three elements play an important role in helping engineers to contextualize their design work during the stage of visualizing and presenting created model for new product development process.
\end{abstract}

Keywords - Contextual Knowledge, Computer Aided Design, Engineering Education

\section{Introduction}

In recent years, many studies have been conducted to improve the level of contextual competencies among engineering undergraduates [1][2]. Good level of contextual competence helps to improve their understanding and establishing their place in the profession in engineering design works [3][4]. The importance to promote contextualization ability among engineering undergraduates in engineering practice also has been stressed in the ABET program accreditation under the criteria of 3.c, 3.f, 3.h and 3.j [3]. In 3D CAD modeling practiced, the advancement of contextual 
knowledge is very important to enhance the ability of engineers in developing a creative and innovative product design as highlighted by Grasso and Burkins [5].

However, results from structured interviews of a preliminary study, have shown that there is a lack of contextual knowledge in the applications of 3D CAD modeling among Mechanical Engineering undergraduates and fresh graduate engineers. Due to lack of this knowledge, it has caused the product designers to not be able to contextualize their models of a good design for the users and manufacturing applications. Ma and Zhang [6] reported that there are some mistakes that often performed by the product designers. They normally consider more on the function of the product instead of manufacturability aspect of parts during the design stage and this has caused some of the parts that were unable to be machined in the manufacturing stage. Therefore, this study has been conducted to improve engineering undergraduates' contextual knowledge in the application of 3D CAD modeling software in engineering design task and towards achieving the reformation initiative in shaping the future of engineering education. The main aim of the study is to develop a framework of contextual knowledge that can be used to enhance fundamental knowledge among Mechanical Engineering Undergraduates in the utilization of 3D CAD modeling software. The questions of what are the essential elements of contextual knowledge in the application of 3D CAD modeling in creating a product design from the practicing engineers' experiences and how the practicing engineers employ the essential elements in the application of 3D CAD modeling within the five contexts of digital product modeling (Model Creation, Model Manipulation, Model Visualization, Model Transfer and Database and Files Management are answered in this study. In this article, the finding of the essential contextual knowledge elements in Model Visualization process that have been utilized among practicing engineers in their daily design work are presented. This article is conceptually structured to introduce the significance of contextual knowledge in learning 3D CAD modeling and subsequently, inform the engineering education community about the presence of contextual knowledge in the 3D CAD modeling process.

\section{Theoretical Framework}

This study is underpinned by the theory of cognitive constructivism. This theory is based Piaget's work on the individual knowledge construction. According to this theory, individual knowledge construction can be construct through cognitive process of analyzing and interpreting experiences [7]. According to Al Mulhem [8], the focus of this theory is more on how learners construct meaning and understanding through active discovery and exploration of the world around them.

In the application of 3D CAD modeling for product design development, practicing engineers actively construct their design knowledge based on their own experiences in during their previous design projects. Through the experiences, they re-organize their experiences and cognitive structures to suit with a new 3D CAD model development. In cognitive constructivism theory, Piaget calls this process as assimilation and 
accommodation [9][10]. The assimilation process occurs when individual faces a new experience and that experience is fitted into an existing mental structure [11]. Whereby, accommodation is a process when there is some modification or conflict with the existing knowledge according to the new experiences it need to be revised to fit with new situations [10][12].

In the context of this study, the assimilation and accommodation process plays an important role among practicing engineers in order to guide them to enhance their contextual knowledge during 3D CAD model development process. Practicing engineers were generally utilizing $3 \mathrm{D}$ CAD modeling software to speed up the process of product design development. In every project that they received, the project has their own criteria, specifications, standards and requirements. They need to make sure all of the requirements are met. Therefore, they need to assimilate and accommodate their existing design knowledge to complete their job.

Throughout the construction process of 3D CAD models, practicing engineers will encounter new ways of representing model's features or alternative procedures to create an object. Thus, they need to construct and reconstruct their own mental models by accommodating the new information [11]. Through the process of model construction and reconstruction activities, it helps the generation of contextual knowledge about the modeling techniques. This shows that the development of contextual knowledge in 3D CAD modeling is constructivist naturally. If new knowledge is developed progressively, then more complex models can be created. In this context, the way how practicing engineers represent their contextual knowledge in $3 \mathrm{D}$ CAD modeling depends on their prior knowledge in the modeling techniques and their contextualization about the model development process. A schematic representation of the theoretical framework is as shown in Fig. 1.

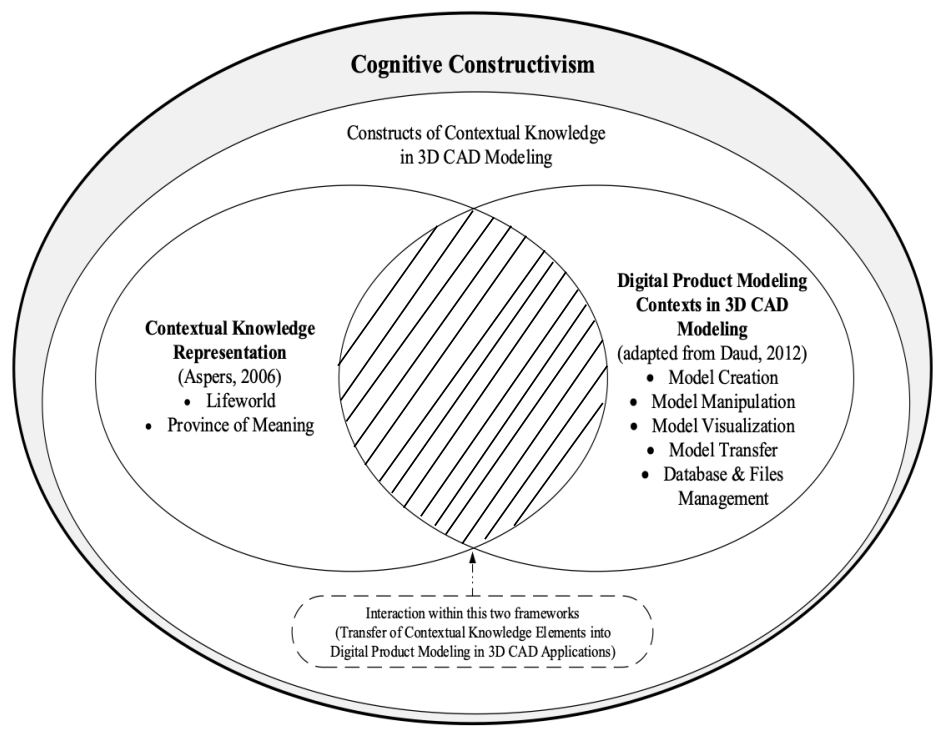

Fig. 1. Theoretical Framework of Research 


\section{Contextual Knowledge in 3D CAD Modeling}

Individual achievement in completing engineering design task depends on knowledge embedded inside their cognitive mind [13]. Tennyson and Breuer [14] stated that in education domain, there are three types of knowledge and known as declarative knowledge, procedural knowledge and contextual knowledge. Based on the problem explained in the previous section, knowledge known as contextual knowledge was explored in this study. According to Tennyson and Breuer [14], contextual knowledge is known as the individual's understanding to employ specific concepts, rules and principles in the knowing of why, when and where the knowledge should be used to complete a particular task. There are two main elements introduced by Aspers [15] to represent contextual knowledge: lifeworld and province of meaning. The lifeworld is referring to the lived and experienced world and thus, it is something more than the world itself rather than the subject itself [16]. The province of meaning refers to the understanding the meaning of a picture or seeing it in the same way that someone else does is a result of shared experiences, schooling and other similarities [17]. These two elements are crucial for solving the real-world problems and the role of contextual knowledge is to help an agent behave quickly, automatically and appropriately for its current problem-solving situation [18].

In 3D CAD Modeling, contextual knowledge can be defined as an individual's understanding of why, when and where to employ specific concepts, rules and principles in completing modeling activities within five digital product modeling contexts: model creation, model manipulation, model visualization, model transfer and database and file management. As mentioned before, lifeworld and province of meaning are the two main elements of contextual knowledge. These two elements have been adapted for this study in exploring contextual knowledge among practicing engineers. Therefore, these elements are redefined into the contexts of this study. The lifeworld element in this study is known as the practicing engineer's knowledge on the real problems, situations and applications face by them when applying 3D CAD modeling activities within five digital product modeling context in their product design [13]. For the element of province of meaning, it has been defined as the practicing engineer's knowledge in having same understanding on the application of 3D CAD modeling activities within digital product modeling context with others engineers in the same manufacturing firm and also they know what their customers want [13].

Table 1 shows example of the significance of contextual knowledge element in 3D $\mathrm{CAD}$ modeling process. In the real design world of a manufacturing, these two elements play an important role during product design using 3D CAD modeling software. For example, in considering safety elements. The engineer needs to think before designing the product by using 3D CAD modeling software to make sure the final product is workable and safe for users. In practice of 3D CAD modeling, filleting or chamfering of sharp edges are meant for safety. Therefore, these essential elements of lifeworld and province of meaning when using 3D CAD modeling are explored in this study. 
Table 1. Contextual Knowledge in 3D CAD Modeling Process

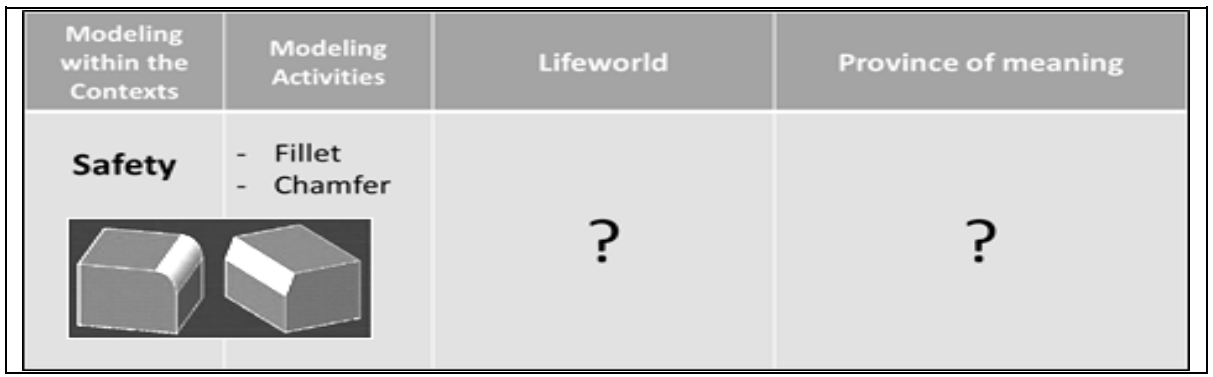

\section{$4 \quad$ Model Visualization in CAD Modeling}

In recent years, the application of powerful graphical processors in computer systems has brought a demand for enhanced quality of visualization [19]. Model visualization is one of the main tasks in CAD modeling that user normally does during the creation and modification of the part modeling and assembly modeling process.

In this model visualization context, the exploration of essential elements practiced by practicing engineers to visualize the creation of models during the process of model development is the main focus. According to Gero [20], the techniques in model visualization of CAD include the tasks of selecting, filtering or highlighting particular aspects of a model to gain better understanding of the structure of a model. 3D CAD system is important to display, share and communicate non-contextual information, (such as product designs and engineering drawings) and allow designers to explore complex model to test problems of interference between components [21].

In the process of product development, there are various forms of drawing that have to be produced by model developer to visualize the model in great detail. There are orthographic, sectional, isometric, perspective, exploded and assembly drawing. According to Sorby et al. [22], all of these drawings are often referred as working drawings. It is also stated that working drawing provide documentation for the sequence of design in product development process. This study explores how the practicing engineer visualizes created model into the drawing form and what are the essential elements that need to be included in drawings to make sure others are able to understand the meaning of the drawing and easily comprehend the drawing.

\section{$5 \quad$ Research Methodology}

A qualitative research design by following a transcendental phenomenology approach was utilized to explore the story of practicing engineers experienced in utilizing the elements of contextual knowledge in 3D CAD modeling application in their daily design work. This transcendental phenomenology approach helps the researcher to be more focused on the description of the practicing engineers' 
experiences and less on the researcher interpretations. Four practicing engineers from a Shipbuilding Company in Peninsular Malaysia was selected via homogeneous sampling scheme [23, 24, 25]. This sampling allowed for an in-depth and representative look at the practicing engineers' contextual knowledge in developing 3D CAD models. The selections of practicing engineers as respondents for this study are restricted to samples with experience in using any types of 3D CAD modeling software with a minimum three years of their daily job with 3D CAD modeling software. As recommended by the engineering professional bodies, three years practical experiences are considered as professional engineer in their work field [26]. The demographic information of the four practicing engineers is as shown in Table 2. In capturing a good description of experiences from practicing engineers' in this study, Husserl's concepts of epoche (or bracketing) has been employed by "set aside own experiences as much as possible to take a fresh perspective toward the phenomenon under examination of this study" [27]. A series of phenomenological interviews and document analysis method has been conducted to collect the data for this study. The phenomenological interview took around one and half hours per session during their free time. The interview session was conducted periodically in four series starting from March 2014 until March 2015. The Moustakas [28] phenomenological interview guidelines were utilized during interview sessions. According to Kennedy [29], conducting the phenomenological interview makes the researcher to keep the questions open and free from preconceived notions and leading terms, allowing for more interviewee-guided rich narrative of a phenomenon.

Table 2. Practicing Engineers Background

\begin{tabular}{|c|c|c|c|c|c|c|}
\hline $\begin{array}{c}\text { No. of } \\
\text { Practicing } \\
\text { Engineers }\end{array}$ & Gender & $\begin{array}{l}\text { Position in the } \\
\text { company } \\
\text { (Technical } \\
\text { Executive = } \\
\text { Engineer) }\end{array}$ & $\begin{array}{c}\text { Years of } \\
\text { experience in } \\
\text { using CAD } \\
\text { software(years) }\end{array}$ & $\begin{array}{c}\text { Types of CAD } \\
\text { software has been } \\
\text { used }\end{array}$ & \begin{tabular}{|}
$*$ Personal skill \\
level or working \\
knowledge in \\
using CAD \\
software (Novice \\
1 à 5 Expert)
\end{tabular} & $\begin{array}{l}\text { Educational } \\
\text { Background }\end{array}$ \\
\hline 1 & Female & $\begin{array}{l}\text { Senior Technical } \\
\text { Executive }\end{array}$ & 9 & AutoCAD, PDMS & 4 & $\begin{array}{l}\text { Mechanical } \\
\text { Engineering }\end{array}$ \\
\hline 2 & Male & $\begin{array}{l}\text { Senior Technical } \\
\text { Executive }\end{array}$ & 6 & $\begin{array}{l}\text { AutoCAD, } \\
\text { SolidWorks, } \\
\text { CATIA, AVEVA }\end{array}$ & 4 & $\begin{array}{l}\text { Mechanical } \\
\text { Engineering }\end{array}$ \\
\hline 3 & Male & $\begin{array}{l}\text { Technical } \\
\text { Executive }\end{array}$ & 11 & $\begin{array}{l}\text { AutoCAD, RDM6, } \\
\text { MAXSURF, } \\
\text { HYDROMAX }\end{array}$ & 5 & $\begin{array}{l}\text { Naval } \\
\text { Architecture } \\
\text { and } \\
\text { Shipbuilding }\end{array}$ \\
\hline 4 & Female & $\begin{array}{l}\text { Technical } \\
\text { Executive }\end{array}$ & 5 & $\begin{array}{l}\text { AutoCAD, } \\
\text { AVEVA, Maxsurf }\end{array}$ & 4 & $\begin{array}{l}\text { Mechanical } \\
\text { Engineering }\end{array}$ \\
\hline
\end{tabular}

* as rated by the department superior

Then, interviews data were analyzed using the Stevick-Colaizzi-Keen modification phenomenological analysis method by Moustakas [28]. This phenomenological analysis was chosen based on the underpinning process of this analysis that has helped the researcher to answer the research questions of this study and allowed the researcher to capture rich descriptions of the participants' experiences. The analysis 
began after all the interviews data has been transcribed. All the interviews transcriptions then were continued with the horizonalization analysis process to find significant statement from each practicing engineers [28]. A total number of 35 significant statements that related to the utilization of contextual knowledge in $3 \mathrm{D}$ $\mathrm{CAD}$ model visualization have emerged from the horizonalization process. Then, all listed significant statements were used to construct the textural descriptions to capture on what are the essential contextual knowledge elements from each practicing engineers in the application of 3D CAD model visualization contexts. Subsequently, structural descriptions were formed to summarize details on how practicing engineers employed the essential contextual knowledge elements in the application of 3D CAD model visualization contexts. In forming the main theme of this study, the textural and structural descriptions were integrated to provide a synthesis of the meanings and essences of the practicing engineers' experience. Relevant documents such as printed engineering drawing, drawing standard and guidelines were also collected from the engineers as supported data to increase the reliability of the interview findings. A whole visual representation of this operational research framework is shown in Fig. 2.

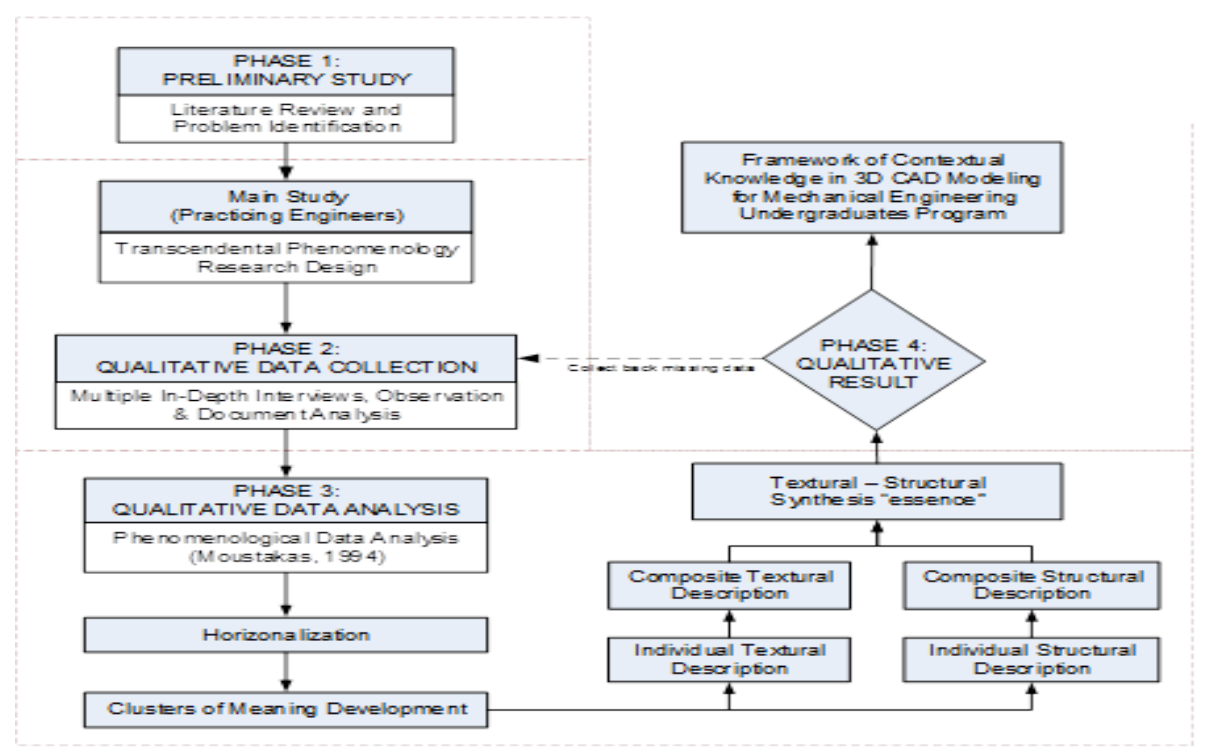

Fig. 2. Visual Representation of Operational Research Framework.

\section{$6 \quad$ Research Findings and Discussion}

This article presents the findings from the exploration of the practicing engineers' contextual knowledge application when using 3D CAD modeling software to create a product design. Answers for the question of what are the essential elements of contextual knowledge in the application of 3D CAD modeling during model visualization stage from the practicing engineers' experiences and how the practicing 
engineers employ those essential elements in the application of 3D CAD modeling are discussed in this section. Three most frequent themes emerge in the application of contextual knowledge in visualizing a model using 3D CAD modeling are: Realization, Design Intention and Normalization.

\subsection{Realization}

In this study, realization is defined as the element that engineers need to utilize the action of the imagination to form an engineering drawing that bringing something vividly to productions or users' application. By realizing the productions or users' application, it helps engineers to create a good model that is more friendly to users and manufacturers. The following section discussed the realization elements that need to be alerted by engineer when visualizing a 3D CAD model.

Produce drawing that able to help others easy to visualize created model: In visualizing a created model for product development, engineer needs to produce a drawing that is able to help others to visualize created model. They need to understand with the type of drawing need to be produced, setting of the appropriate size of paper and drawing scale to visualize created model. As mentioned by one of the practicing engineers in this study, she said that:

"Then we will extract the created model into a drawing form. There are construction drawing assembly drawing sub-assembly drawing and etc. So, we need to decide which type of drawing we want to produce for me, it's very important to select the correct drawing type to make sure the production site clear with the design we want them to produce" (PE 1)

From the above statement, it shows that there are several aspects that need to be considered by engineers to make others easily visualize created model into the drawing form.

Produced drawing that conscious with others and easily readable and understand created model

As engineer, when in the process to visualize the created 3D CAD model, they need to make sure their produce drawing that is easy to read and understand by others. This aspect is very important in making their created model to form products accordingly. As stated by one of the practicing engineers:

"When constructing a production drawing, I'm always stressing on the aspect of making others easy understand what I want they to do...I will make sure my drawing and views arrangement is follow the development process. sometimes I will go directly to production site to discuss with them about my drawing arrangement is ok or not do they understand what I meant in my drawing or not" (PE 4)

According to the above statement, it shows that when visualizing a model, we need to realize the ability of others to read and understand with what we mean in our drawing. By realizing this aspect, it can help others to speed up the product development process.

Produce drawing with awareness of the critical part in a model: During visualizing created model, engineers need to be aware with the critical section of a model in real world. They need to highlight this part in their drawing by inserting 
details view or sectional view. The following is one of the statement from a practicing engineer during the interview session. He said that:

"When extracting the created model into production drawing, we need to note which part is needed to add the details view to show the critical part and sometimes we like to cut the part and show the sectional view of the part. We add this view because when the orthographic view cannot show that critical part"(PE 2)

Base on that statement, it shows that there is a need for engineers to make sure the critical parts are highlighted in the production drawing. If this aspect is neglected, it will affect production team's understanding of created model in the development process.

The above statement has been supported by drawing shown in Fig. 3. In this generator foundation assembly drawing, it shows the importance of engineers to highlight the important parts or components in the assembly or manufacturing drawing. This action will optimize the production process.

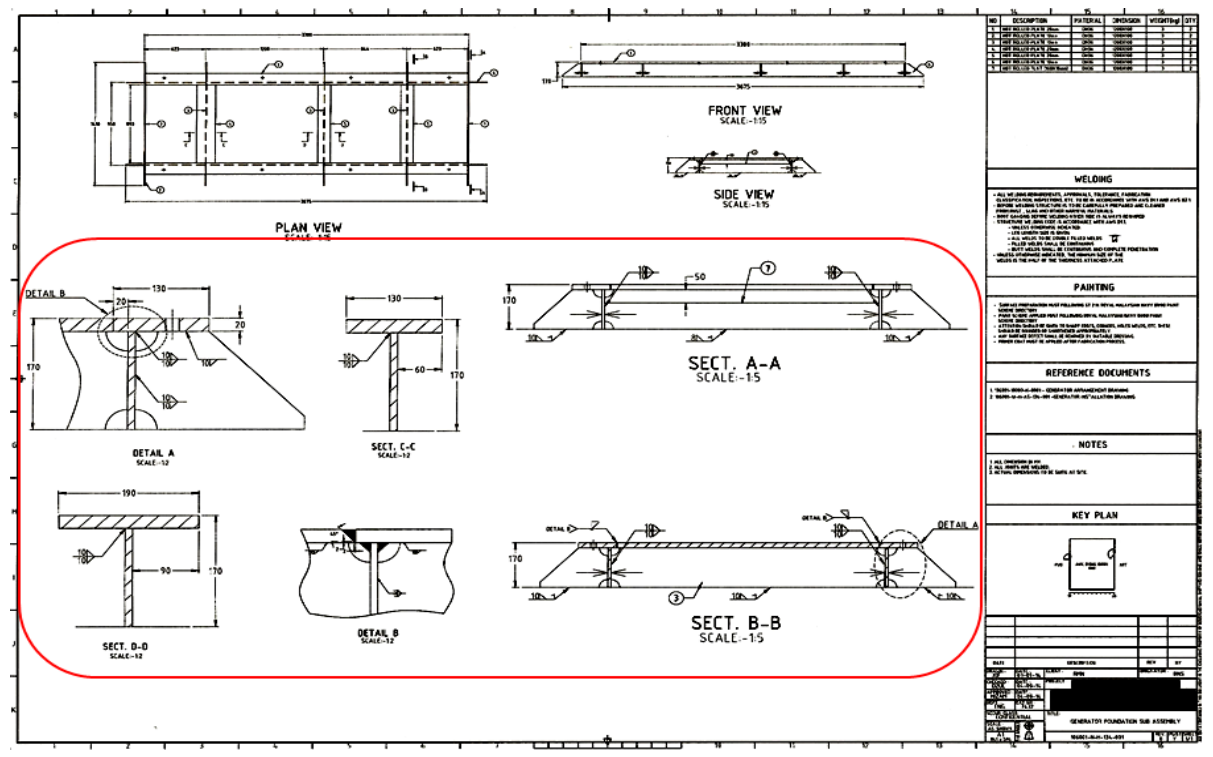

Fig. 3. Sample of Sectional and Detail View Applications in Drawing

Produce drawing that able to communicate with production site: In product development process, production drawing plays an important role in making the created model become realize. Good drawing quality will able to communicate with the production site effectively. Thus, as an engineer, they need to make sure that the drawing has been fully drawn with a clear information like the dimension of the part, part details, drawing scale and others. According to one of the practicing engineers from this study, he said that:

"After complete inserting the orthographic view, then we will start to insert the dimensions on the top, front and side view But, we need to make sure the dimension is 
enough and clear to give the information on the created model for manufacturing process" $(\boldsymbol{P E}$ 1)

From the above statement, it means that engineers need to produce good drawings that can represent their design model to suit the nature of the manufacturing stage.

\subsection{Design Intention}

As discussed in the previous section, design intention of this study is defined as an element that engineer need to plan on how the creation part of should be visualized and presented in an engineering drawing to accomplish the product development process. The following section discussed the essential elements of design intention.

Produce drawing that follow the manufacturing process: During producing a drawing, the engineer needs to make sure the arrangement of part or assembly views is followed with the manufacturing process. This element is very important to be practiced by engineer during the engineering drawing development process. By following this element, it will help the production site to easily plan on what are the process involve to fabricate created model. From the interview session, one of the practicing engineers mentioned that:

"I try to imagine how the created design will be fabricated by the production site. I will think like I'm as the fabricator of my design. So, based on that type of thinking I will know which view of the part needs to be highlighted in the drawing which part will be produced first...is that ok if I put this view first or not" (PE 3)

Thus, based on the above statement, as engineers, they need to make sure created drawings are well arranged and are according to the practices of the manufacturing process.

Produce drawing that follow required standard: In CAD modeling, there are a lot of CAD drawing standards. Especially for drawing dimensions and labels. Among them are ISO, ANSI, ASME, DIN and others. The CAD standards are sets of rule and styles for the way CAD drawings should appear. As an engineer, they need to follow the common type of CAD drawing standard when visualizing created 3D model. They need to set the dimension styles, line types, text styles and others. According to one of the practicing engineers in this study, she mentioned that:

"we need to know about CAD standard to use If we select a wrong standard, it will effect the appearance of our drawing for example, if we choose ISO dimension style for our drawing and then we know that is a wrong standard and need to change to ANSI standard. Actually, when we change the standard for dimension style, this drawing appearance will be different from the previous so, we need to take a times to make a corrections" (PE 2)

The above statement actually showing that, it is very important to select the correct standard of CAD drawing during the drawing development process. It must be based on the drawing standard that has been set by the company in order to make sure all the produced drawings are standardized.

Produce drawing that based on their purpose: Knowing the purpose of each type of an engineering drawing is very important. By understanding the intent on each drawing types make the engineer able to focus and producing a good production 
drawing for product development process. In practiced, there are part drawing, assembly drawing, sub-assembly drawing, nesting drawing and others. As mentioned by one of the practicing engineers in this study, she said that:

"We will produce a set of production drawing for product construction. There is the assembly drawing that shows the complete part of design from front top side view. Then, there will have sub-assembly drawing that show the details part involves in that product ha ah, this one is construction drawing this drawing will show the details on part involved and need to construct this drawing is in $2 D$ we call as orthographic drawing"(PE 1)

According to the above statement, it explained that each type of drawing has their own purpose. As an engineer, they need to clearly understand the purpose of the drawing in visualizing their created 3D model for product development process.

\subsection{Normalization}

Normalization is the third theme emerged from data analysis. In this study, normalization is known as the element that helps the engineer to make created model to be visualized in accordance with the current standards and requirements practiced in engineering drawing. The following section discussed three aspects that need to be considered by engineers in the process of visualizing a product design.

Produce drawing based on typical practices of drawing format: In one sheet of engineering drawing, there are many formats of characters need to be included. There are the format for title block characters, dimension characters, label characters, scale label characters, revision label characters and others. As stated by one of practicing engineers in this study, he mentioned that:

"In every drawing that we produce, we need to note their drawing revision...in our company's practiced, we will set the first version as "Rev.0". If there is some modification in that drawing like the dimension or part specs, we will update the revision as "Rev.A" " (PE 4)

From the statement, it shows the importance of the engineers to know and apply the practice of drawing format during drawing development process. Fig. 4 shows the application of drawing revision in the drawing block. Therefore, when producing the engineering drawing, engineers need to apply the typical practices of drawing format to visualize their created drawing or model. 


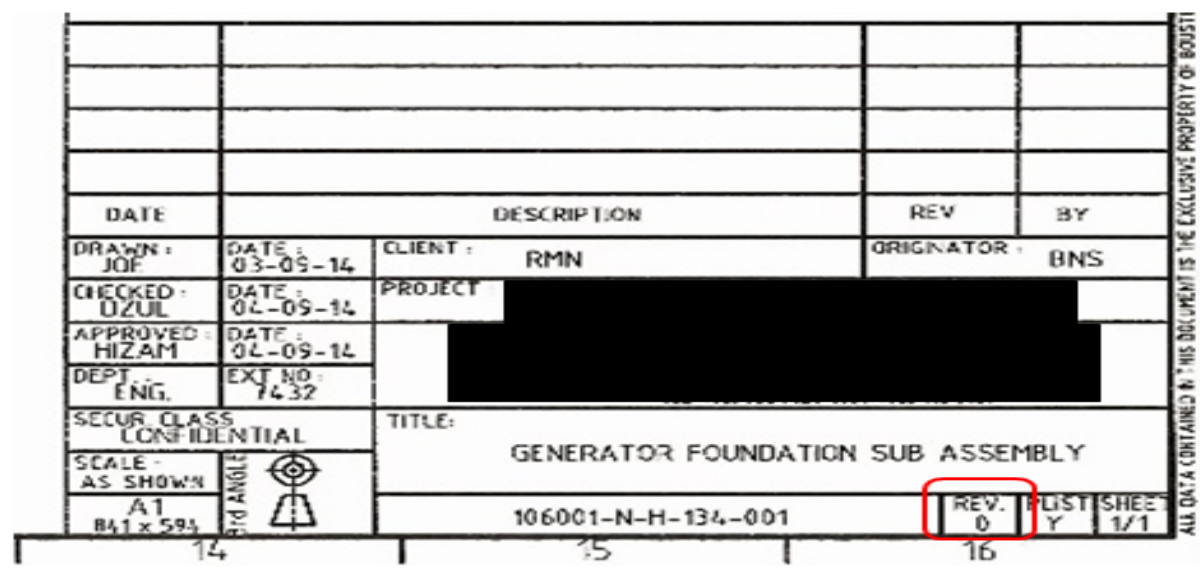

Fig. 4. Sample of Revision Note Applications in Drawing

Produce drawing that follows the common standard of practices: Commonly, there are many standards need to be followed in developing an engineering drawing. There are standards for drawing reference number, dimension and label, projection type and others. As engineers, they need to know and apply their company practiced standard. According to one of practicing engineer in this study, she mentioned that:

"Every drawing we create, we will set the drawing reference number. This reference number is very important to track the created drawing. So, to create this drawing reference number, we will follow the company's standard. For example, this drawing reference number is "102001-63000-K-0003"... from this reference number, there is an alphabet of ' $K$ '. This ' $K$ ' actually stand for the construction drawing type if 'AS', it mean that is assembly drawing" (PE 1)

By applying the standards of practices in the produce drawing, it will produce more standardized drawings.

Produce drawing that follows the common drawing arrangement: Normally, there will be a set of drawings received by production site to fabricate the created design. As an engineer, we need to make sure the produce drawing are well arranged to make sure the fabricator can produce a good product as intended. From the interview session, one of the practicing engineer in this study mentioned that:

“In our company's practice, we like to arrange our created model by using $3 \mathrm{rd}$ angle projection... because by using this type of projection, it actually will help others easy to understand the overall shape of our created design...because in 3rd angle projection, it will showing less hidden line" (PE 3)

The above statement shows that there are several aspects should be followed by the engineers during the model visualization process. The application of 3 rd angle symbol in the drawing block is as shown in Fig. 5. 


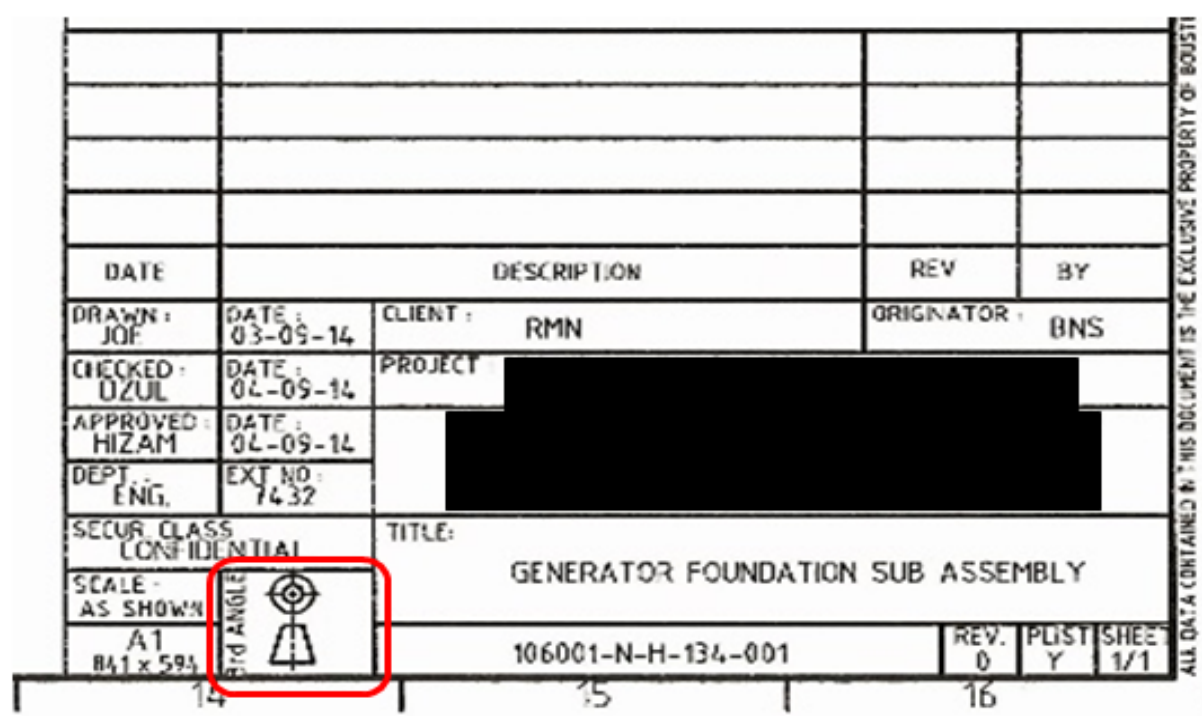

Fig. 5. Sample of 3rd Angle Symbol Applications in Drawing Block

\section{Conclusion}

This article discusses the findings of the study that explore the essential elements of contextual knowledge in the process of visualizing a 3D model from practicing engineer experiences. Based on the present findings, three main elements of contextual knowledge emerged in this study. There are the elements of Realization, Design Intention and Normalization. These three elements play important roles in helping the engineers to contextualize their design work during the stage of creating a good 3D model for new product development. By utilizing the element of realization, it will help engineers to utilize the action of the imagination to form an engineering drawing that bringing something vividly to productions' or users' applications. Therefore, the element of design intention will help the engineers to plan on how the creation part need to be visualized and presented in an engineering drawing to accomplish the product development process and then, the element of normalization will make the creation model are visualized in accordance with the current standards and requirements practiced in engineering drawing.

\section{Acknowledgement}

The authors would like to thank the Centre for Engineering Education (CEE) UTM, for supporting this research project. 


\section{$9 \quad$ References}

[1] Ro, H. K., Merson, D., Lattuca, L. R., \& Terenzini, P. T. (2015). Validity of the contextual competence scale for engineering students. Journal of Engineering Education, 104(1), 3554. https://doi.org/10.1002/jee.20062

[2] Atman, C. J., Yasuhara, K., Kilgore, D., Atman, C. J., Yasuhara, K., \& Kilgore, D. (2014). Assessment techniques for contextual competence: A resource for teaching and learning engineering design. Seattle, WA: Center for Engineering Learning \& Teaching.

[3] Engineering Accreditation Commission. (2014). Criteria for Accrediting Engineering Programs. Effective for Reviews during the 2015-2016 Accreditation Cycle. ABET, USA.

[4] Clough, G. (2005). Educating the engineer of 2020: Adapting engineering education to the new century. National Academy of Engineering, Washington, DC.

[5] Grasso, D., \& Burkins, M. (Eds.). (2010). Holistic engineering education: Beyond technology. Springer Science \& Business Media.

[6] Ma, G., \& Zhang, F. (2010). Plan Based Automated Generation of Redesign Suggestion. In Proceedings of the World Congress on Engineering and Computer Science (Vol. 1).

[7] Akar, H. (2003). Impact of constructivist learning process on preservice teacher education students' performance, retention, and attitudes (Doctoral dissertation, METU).

[8] Al Mulhem, A. (2014). Developing an e-learning training package for academic staff in one university in Saudi Arabia.

[9] Cholewinski, M. (2009). An introduction to constructivism and authentic activity. Journal of the School of Contemporary Society International Studies Nagoya University.

[10] Can, T. (2009). Learning and teaching languages online: A constructivist approach. Novitas-Royal, 3(1).

[11] Piaget, J., \& Inhelder, B. (2008). The psychology of the child. Basic books.

[12] Slavin, R. E. (2018). Educational Psychology: Theory and Practice, 12th ed. Needham Heights, MA: Allyn and Bacon.

[13] Adnan, M. F., Daud, M. F., \& Saud, M. S. (2014, April). Contextual Knowledge in Three Dimensional Computer Aided Design (3D CAD) Modeling: A Literature Review and Conceptual Framework. In 2014 International Conference on Teaching and Learning in Computing and Engineering (pp. 176-181). IEEE. https://doi.org/10.1109/latice.2014.41

[14] Tennyson, R. D., \& Breuer, K. (2002). Improving problem solving and creativity through use of complex-dynamic simulations. Computers in Human Behavior, 18(6), 650-668. https://doi.org/10.1016/s0747-5632(02)00022-5

[15] Aspers, P. (2006). Contextual knowledge. Current Sociology, 54(5), 745-763. https://doi. org/10.1177/0011392106066814

[16] Dahlberg, H., \& Dahlberg, K. (2003). To not make definite what is indefinite: A phenomenological analysis of perception and its epistemological consequences in human science research. The Humanistic Psychologist, 31(4), 34-50. https://doi.org/10.1080/088 73267.2003.9986933

[17] Aspers, P. (2006). Designing for the other: using knowledge to upgrade manufacturing in the garment industry.

[18] Brézillon, P. (1999). Context in Artificial Intelligence: II. Key elements of contexts. Computers and artificial intelligence, 18, 425-446.

[19] Horváth, L., \& Rudas, I. (2004). Modeling and problem solving techniques for engineers. Elsevier.

[20] Gero, J. S. (1994, January). Towards a model of exploration in computer-aided design. In Formal design methods for $\mathrm{CAD}$ (pp. 315-336). 
[21] Yassine, A., Kim, K. C., Roemer, T., \& Holweg, M. (2004). Investigating the role of IT in customized product design. Production Planning \& Control, 15(4), 422-434. https://doi. org/10.1080/0953728042000238782

[22] Sorby, S. A., Manner, K. J., \& Baartmans, B. G. (1998). 3-D visualization for engineering graphics. Upper Saddle River, NJ: Prentice Hall.

[23] Patton, M. Q. (2014). Qualitative research and evaluation methods (4th edition). Thousand Oaks, CA, Sage.

[24] Teddlie, C., \& Yu, F. (2007). Mixed methods sampling: A typology with examples. Journal of mixed methods research, 1(1), 77-100. https://doi.org/10.1177/15586 89806292430

[25] Creswell, J. W. (2018). Educational Research: Planning, Conducting, and Evaluating Quantitative and Qualitative Research, (6th Edition). Pearson Education International.

[26] Engineering Accreditation Commission. (2016). Registration of Engineers Act 1967 (Revised 2015). BEM, Malaysia (pp. 71).

[27] Creswell, J. W., \& Poth, C. N. (2017). Qualitative inquiry and research design: Choosing among five approaches. Sage publications.

[28] Moustakas, C. (1994). Phenomenological research methods. Sage.

[29] Kennedy, K. M. (2010). The Essence of the Virtual School Practicum: A Phenomenological Study of Pre-service Teachers' Experiences in a Virtual School (Doctoral dissertation, University of Florida).

\section{Authors}

Mohd Fahmi Adnan is a $\mathrm{PhD}$ student in engineering education at Universiti Teknologi Malaysia (UTM), Skudai, Johor, Malaysia. He is a lecturer in the Department of Electrical and Electronic Technology at Kota Tinggi Vocational College, Johor. His research areas include Computer Aided Design (CAD), contextual knowledge and phenomenological research in engineering education.

Mohd Fadzil Daud is Academic Manager of the UTM Centre for Engineering Education (CEE), Skudai, Johor, Malaysia, which promotes meaningful research and scholarly practices in engineering education. He is also working as senior lecturer at the Faculty of Mechanical Engineering in the Department of Applied Mechanics \& Design. His engineering education research focuses on conceptual knowledge in 3D CAD modeling and engineering service learning.

Muhammad Sukri Saud is Dean of the UTM Faculty of Social Sciences and Humanities, Skudai, Johor, Malaysia. He is also working as professor in the Department of of Technical and Engineering Education. His research areas include curriculum design and development in engineering, technical and career education.

Wan Nazdah Wan Hussin is senior lecturer at the Faculty of Mechanical, UTM Skudai, Johor, Malaysia. She is working under the Department of Materials, Manufacturing \& Industrial Engineering. Her research areas include dynamic job shop scheduling model for small and medium-sized companies.

Article submitted 2019-09-30. Resubmitted 2019-10-27. Final acceptance 2019-11-04. Final version published as submitted by the authors. 